\title{
EFFECTS OF SUBLIMINAL PRIMING ON NONCONSCIOUS GOAL PURSUIT AND EFFORT-RELATED CARDIOVASCULAR RESPONSE
}

\author{
Rémi L. Capa \\ University of Liège, Department of Cognitive Sciences, Belgium \\ Axel Cleeremans \\ Université Libre de Bruxelles, Consciousness, Cognition, \& Computation Group, Belgium \\ Gaëlle M. Bustin \\ University of Liège, Department of Cognitive Sciences, Belgium \\ Cédric A. Bouquet \\ University of Poitiers, Centre de Recherches sur la Cognition et l'Apprentissage-CNRS \\ Michel Hansenne \\ University of Liège, Department of Cognitive Sciences, Belgium
}

\begin{abstract}
Building on the work of Aarts and coworkers on nonconscious goal pursuit, the present study investigates whether subliminal processes may motivate effortful behavior and perseverance to learn coursework. We exposed students to a priming task in which subliminal representation of the goal of studying was directly paired (priming-positive group) or not (priming group) to a positive word. There was also a control group without subliminal prime of the goal. Next, students performed a learning task based on their coursework. Participants in the priming-positive group exhibited across time on task a larger decrease of midfrequency band of heart rate variability and a larger decrease of the pulse transit time related to effort mobilization than participants in the control group and the priming group, respectively. These findings provide the first evidence that subliminal priming can induce a greater cardiovascular reactivity suggesting effortful behavior and perseverance when pursuing a simple goal typical of daily life.
\end{abstract}

\footnotetext{
We thank Lionel Naccache and Chris Frith for helpful comments on earlier drafts. Axel Cleeremans is a Research Director with the Fonds de la Recherche Scientifique-FNRS.

Correspondence concerning this article should be addressed to Rémi L. Capa, University of Liège, Department of Cognitive Sciences, 5 Bd. du Rectorat B-32, 4000 Liège, Belgium. E-mail: remi.capa@ ulg.ac.be

(c) 2011 Guilford Publications, Inc
} 
Goals are the tools with which individuals engage in volitional behavior (Dijksterhuis \& Aarts, 2010). Priming of goal representations can promote effort to attain this goal (Aarts, Gollwitzer, \& Hassin, 2004; Bargh, Gollwitzer, Lee-Chai, Barndollar, \& Trötschel, 2001). For example, Bargh et al. (2001) showed that activation of achievement goals via exposure to visible words such as succeed and win exerts an unconscious influence on effort mobilization in a subsequent word search task. Most of these studies used supraliminal stimuli to prime nonconsciously goal pursuit. As outlined by the taxonomy of conscious, preconscious, and subliminal processing established by Dehaene, Changeux, Naccache, Sackur, and Sergent (2006) and Koch and Tsuchiya (2007); supraliminal stimuli could quickly gain access to conscious report if they were attended and only stimuli masked and presented subliminally ensured a strict unconsciousness. One implication is that subliminal and supraliminal stimuli displayed frequently a differential pattern of response and differential origins of the response (Van den Bussche, Hugues, Van Humbeeck, \& Reynvoet, 2010). Very few studies have used subliminal processes to investigate nonconscious goal pursuit. Building on recent researches conducted by Aarts and colleagues (Aarts, Custers, \& Marien, 2008; Aarts, Custers, \& Veltkamp, 2008; Custers \& Aarts, 2005, 2007), we provide stronger evidence for these subliminal priming effects and show that subliminal priming of the goal to study induces a greater cardiovascular reactivity related to mental effort mobilization.

Goals are conceptualized as mental representations of behaviors or behavioral outcomes that are desirable or rewarding to engage in or to attain (Dijksterhuis \& Aarts, 2010). Aarts and colleagues (Aarts, Custers, \& Veltkamp, 2008; Custers \& Aarts, 2005, 2007) used an evaluative conditioning paradigm (De Houwer, Thomas, \& Baeyens, 2001) to manipulate the cognitive (i.e., mental representation) and the affective features (i.e., desired state) of a goal. Representation of a goal was subliminally primed and directly coactivated with positive words that were consciously visible. As a consequence of this priming, participants reported greater subjective wanting to engage in the primed goal (e.g., solving a puzzle) and expended more effort on tasks instrumental to attain the goal state. Most relevant, a recent study (Aarts, Custers, \& Marien, 2008) showed that participants exerted more physical effort in a demanding force task extending over three seconds after exposure to subliminal word primes related to the goal of physical exertion, but only when the primes were associated with visible positive words. This suggests that subliminal processes may directly induce vigorous behavior toward the achievement of a simple physical goal. Here, we ask whether such processes may also directly induce a greater investment to attain the more abstract goal of studying. We hypothesized that activating the goal of studying through subliminal priming might motivate effortful behavior to learn courses and perseverance across time on coursework, particularly when the goal is co-activated with positive words. This affective valence should signal that the accessible goal is worth pursuing (Aarts, Custers, \& Marien, 2008, Aarts, Custers, \& Veltkamp, 2008; Custers \& Aarts, 2005, 2007).

Following Aarts and colleagues (Aarts, Custers, \& Marien, 2008, Aarts, Custers, \& Veltkamp, 2008; Custers \& Aarts, 2005, 2007), we compared three groups (Figure 1). In the priming-positive group, $50 \%$ of the trials paired directly subliminal priming of words related to study with perceptible positive words. The other half of the trials combined different random letter strings with neutral words. In the priming group, the goal to study was subliminally primed, but not directly paired 


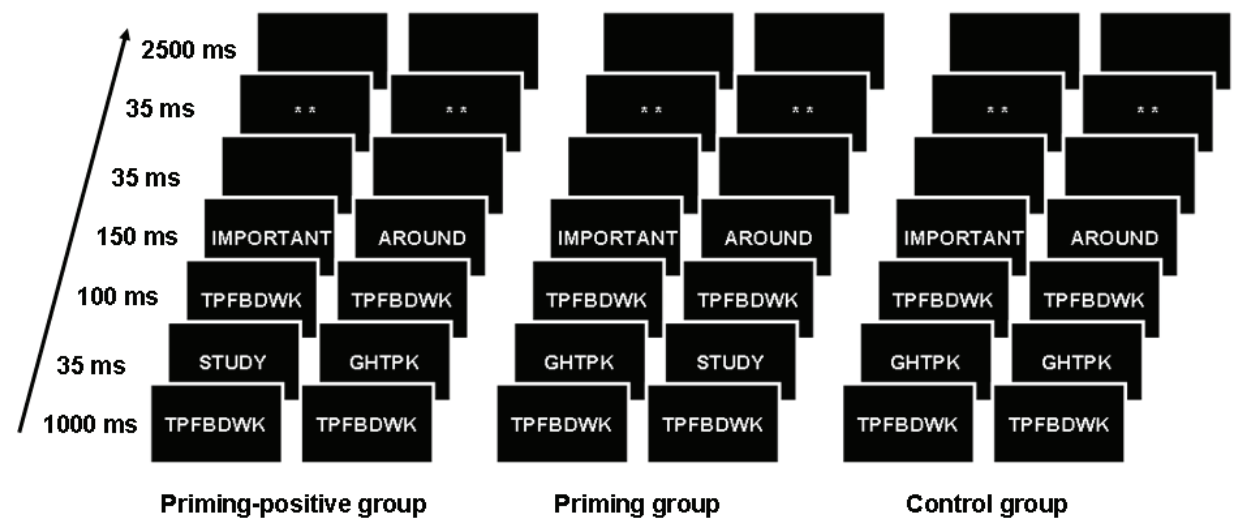

FIGURE 1. Sequences of events used in the priming task as a function of groups.

with positive words. Fifty percent of trials paired words related to study with neutral words, and the other half of trials paired random letter strings with positive words. This group was designed to test the necessity of a direct association between the primed goal and positive words. Furthermore, to test the effect of goal priming, we included a control group in which random letters strings were linked to both positive words and neutral words. After the priming task, participants had to perform a learning task based on their courses.

To test the hypotheses, we focused on cardiovascular reactivity related to effort mobilization. In the current study, several cardiovascular measures were used: heart rate, midfrequency band of heart rate variability, and Pulse Transit Time (PTT). Studies showed that task engagement may be related to an increase of heart rate (e.g., Venables \& Fairclough, 2009). However, heart rate is determined by both sympathetic and parasympathetic activation and should only respond to effort mobilization when the sympathetic impact is stronger (Berntson, Cacioppo, \& Quigley, 1993). Askelrod, Gordon, Ubel, Shannon, Barger, and Cohen (1981) introduced power spectral analysis of heart rate variability to quantitatively evaluate beat-to-beat cardiovascular control. When people are confronted with performance challenges, an increase of sympathetic nervous system activity, related to task engagement (Obrist, 1981; Wright, 1996), induces changes in the midfrequency band ranging from 0.07 to $0.14 \mathrm{~Hz}$ (for a review see Mulder et al., 1995). A decrease of the midfrequency band is associated with mental effort mobilization (e.g., Capa, Audiffren, \& Ragot, 2008a,b; Duschek, Muckenthaler, Werner, \& Reyes del Paso, 2009; Fairclough, Venables, \& Tattersall, 2005). The midfrequency band is a good index of effort mobilization under the condition that this band is not influenced by respiratory activity and parasympathetic nervous system activity (Mulder et al., 1995). Variations in the high-frequency band, from 0.15 to $0.40 \mathrm{~Hz}$, mainly reflect respiratory activity influence and are thought to reflect parasympathetic nervous system activity (Askelrold et al., 1981). Finally, PTT was used as an index of sympathetic nervous system activity (Kemper, Leue, Wacker, Chavanon, Hennighausen, \& Stemmler, 2008; Ravaja, 2004). PTT is the time taken for the pulse to travel between two arterial sites and may be a useful estimate of blood pressure. An increase of blood pressure is associated with a PTT decrease. Conversely if blood 
pressure falls, then the speed of the pulse waveform decreases and PTT increases. PTT has been shown to shorten during effortful tasks (e.g., Tomaka, Blascovich, Kelsey, \& Leitten, 1993).

\section{METHOD}

\section{PARTICIPANTS}

Forty-two psychology students from the University of Liège were randomly assigned to one of the three groups (30 women, age range 19-29 years). Grade levels and participants' gender were counterbalanced across groups.

\section{PRIMING TASK}

In a pilot study, 220 students selected five verbs (e.g., study and memorize) and five adjectives (e.g., important and necessary) that describe the concept of studying on a Likert scale ranging from 1 (completely disagree) to 5 (completely agree) $(M=4.48, S D=.61 ; M=4.20, S D=.84$, respectively). Participants were also asked to evaluate whether adverbs were related to a positive or a negative event on a Likert-type scale ranging from 1 (completely disagree) to 5 (completely agree). Five neutral adverbs (e.g., furthermore and around) were selected $(M=1.34, S D=$ .49). Furthermore, on the basis of another pilot study $(N=24)$, participants were asked to evaluate whether the five adjectives selected (e.g., important and necessary) were related to a positive event on a Likert-type scale ranging from 1 (completely disagree) to 5 (completely agree) $(M=4.01, S D=.86)$. The priming task was presented on an $85-\mathrm{Hz}$ CRT screen. Each trial consisted of the following events (Figure 1): A random letter string was presented followed by a subliminal prime word. A random letter string appeared again, followed by a consciously visible word. Next, one, two, or no dot, were presented without pre and post-mask (hence consciously visible). Participants indicated whether they had seen one, two, or no dot, by pressing the 1, 2, or 0 key of a standard keyboard, respectively. After a 2500 ms blank interval, a new trial started. This procedure ensured that participants paid attention to the words during the task without being aware of the prime. The cognitive processes at work in masked priming experiments are dependent of attention (Naccache, Blandin, \& Dehaene, 2002).

\section{LEARNING TASK}

The task was composed of 40 trials. For each trial, we extracted ten sentences from one specific psychology course (e.g., for the social psychology course, "When an event occurs, the average person spontaneously makes causal: inferences"). Four members of the teaching staff from the University of Liège constructed sentences. We used criteria (i.e., number of words, level of clarity, importance of the topic) to formulate them.

Each trial lasted $35.3 \mathrm{~s}$. Within each trial, the ten sentences were successively presented (2600 ms per sentence). Participants had to read them and memorize the last word. Next, one of the ten sentences was presented again during $2000 \mathrm{~ms}$ with the last word missing. Participants then selected the correct last word in a fourchoice recognition task by pressing on one of four corresponding keys. At the end 
of each trial, participants received feedback on their reaction time. Furthermore, starting signals (fixation cross, square, or triangle) was presented before each trial during $2000 \mathrm{~ms}$. Participants were asked to count the number of squares and triangles while carrying out the learning task. ${ }^{1}$ Participants were instructed to react as quickly as possible without making errors and to count the number of square and triangle.

\section{SUBJECTIVE MEASURES}

To detect potential differences of ability to perform the learning task, participants filled out two subjective difficulty scales. First, perceived workload was assessed using the NASA Task Load IndeX (TLX; Hart \& Staveland, 1988). ${ }^{2}$ The TLX scale provides an overall workload score based on a weighted average of ratings on the six bipolar dimensions of mental demand, physical demand, temporal demand, performance, effort, and frustration. To measure perceived difficulty, we referred to the scale of Eccles and Wigfield (1995). Participants responded on four items, such as "How hard is this task for you?," on a Likert scale ranging from 1 (very easy) to 5 (very difficult). Furthermore, a high frequency of goal pursuit may influence the level of expertise and, consequently, investment and perseverance to attain this goal (Custers \& Aarts, 2007). Therefore, to ensure that the groups were comparable, we also assessed the frequency with which the goal to study was pursued over time. Participants were asked four questions such as "How often do you think about working your courses?" on a 5-point scale from never to very often.

\section{CARDIOVASCULAR MEASURES}

An electrocardiogram (ECG) was recorded using the Psylab Model BIO2 isolated AC amplifier (Contact Precision Instruments, London, UK). Three 16-mm Ag/ $\mathrm{AgCl}$ electrodes (Red Dot, 3M) were placed in a modified Lead II position. Moreover, peripheral pulse signals were recorded using the Psylab Model PPA2 peripheral pulse amplifier, together with a Psylab (Model PT1) photoplethysmograph transducer placed on the finger of participants' left hand. The cardiovascular signal was continuously monitored and digitized online $(500 \mathrm{~Hz})$.

The ECG signal and the peripheral pulse signal were visually inspected. Data considered as artifactual were manually replaced by interpolated or extrapolated data (mean of the three values preceding). The amount of abnormal beats was less than $2 \%$. Four parameters were derived from the cardiovascular recordings. First, the heart rate, beats per minute (bpm), was obtained from R-R intervals of the ECG data. Moreover, in accordance with the Task Force (1996), suitable series of 256 R-R intervals of the ECG data were chosen for spectral analysis of heart rate variability. The fast Fourier transform spectra were calculated from this $256 \mathrm{R}-\mathrm{R}$ interval with HRV analysis software 1.1 for Windows (Niskanen, Tarvainen, Ranta-Aho, \& Karjalainen, 2004). According to Mulder et al. (1995), we used fluctuations in

1. The dual-task condition was used for a main reason. Mulder et al. (1995) found no effect of task engagement on heart rate variability under single-task condition. However, the effects on heart rate variability were only evident under dual-task conditions (i.e., visual memory search task and counting task).

2. In the present article, difficulty and workload are used indifferently. 
the midfrequency band ranging from 0.07 to $0.14 \mathrm{~Hz}$ and the high-frequency band ranging from 0.15 to $0.40 \mathrm{~Hz}$. The spectral power values of the midfrequency and the high-frequency bands were in absolute values of power in milliseconds squared. To approach normal distribution of the data for statistical analysis, the spectral power values were transformed into logarithmic values. Finally, PTT (ms), the interval between the ECG R-wave and the onset of the finger pulse wave, was registered using two Psylab Interval Timers that were linked together. One interval timer registered R-waves while the other, with its analog waveform input linked to the PPA2 amplifier, measured PTT.

\section{PROCEDURE}

After participants signed a consent form, the experimenter installed the photoplethysmograph transducer and the electrodes, and began an 8 min baseline. Participants were instructed to rest quietly. Next, participants performed a training session of the learning task ( 2 blocks of 5 trials). Then, participants performed the priming task and one minute after the learning task. Immediately after completion of the learning task, participants filled out the TLX, the perceived difficulty scale, and the scale concerning the frequency with which the goal to study was pursued.

\section{DATA ANALYSIS}

For the priming task, behavioral and cardiovascular data were examined with a one-way ANOVA (3 groups). For the learning task, subjective data and behavioral data (i.e., error rate in counting the squares or the triangles) were collected at the end of the learning task and were, consequently, examined with a one-way ANOVA (3 groups). Other behavioral data (mean reaction time and error rate in the learning task) and the cardiovascular activity were recorded during the learning task. According to our main hypothesis, these data were examined with a linear polynomial contrast. For each group, a linear relationship across time on task was tested ( 5 successive periods of time). ${ }^{3}$ Contrasts weights were +1 for the group tested and 0 for the other groups. Cardiovascular reactivity scores were calculated by subtracting values from the baseline period from the values of the priming task or the learning task.

\section{RESULTS}

\section{PERCEPTION OF THE PRIME}

In two control experiments, participants were fully informed that a verb or a random letter string was briefly presented between the pre-mask and post-mask and were subjected to the priming and priming-positive treatments. Twenty participants

3. One period of time is composed of 8 successive trials ( $35.3 \mathrm{~s}$ by trial) and lasted 4 minutes and 42 seconds. For mean reaction time and error rate in learning task, one period of time refers to the mean of 8 responses. For heart rate and PTT, one period of time refers to a mean of 4 minutes and 42 seconds of data continuously recorded. For heart rate variability, the fast Fourier transform spectra were calculated from 256 R-R intervals of the ECG data. A period of time of 4 minutes and 42 seconds allowed to select $256 \mathrm{R}-\mathrm{R}$ intervals for each participant and each period. 
had to respond for each of the 100 trials whether they had seen a verb or not and to indicate the perceived verb. No one reported seeing a verb. Moreover, twenty five participants performed a forced-choice test. At the end of each trial, a pair of choices was presented (i.e., the verbs related to study or the random letter strings). They were told that only response accuracy, not response speed was important. The pair of choices remained on the screen until a response was made. The mean percentage of correct responses was $51.76\left(S D=7.21 ; d^{\prime}=.09\right)$, which did not differ significantly from chance, $\chi^{2}(24)=26.52, p>.32$. The two conditions did not differ as well, $p>.74$.

\section{CARDIOVASCULAR BASELINE}

Preliminary, we examined whether the three groups differed between rest periods (Table 1) with a one-way ANOVA (3 groups) for any baseline index. No difference between groups was found (all $p s>.55$ ).

\section{PRIMING TASK}

Behavioral Data. Behavioral data (Table 2) were examined with a one-way ANOVA (3 groups). Analyses of mean reaction time and the arcsinus-transformed proportion of errors revealed no significant difference between groups (all $p \mathrm{~s}>.46$ ).

Cardiovascular Reactivity. Data of cardiovascular activity are presented in Table $2 .{ }^{4}$ Cardiovascular data (heart rate, PTT, midfrequency band, high-frequency band) were examined with a one-way ANOVA (3 groups). No effect of group was found (all $p \mathrm{~s}>$.16).

\section{LEARNING TASK}

Subjective and Behavioral Data. Data are presented in Table 3. Subjective data were examined with a one-way ANOVA (3 groups). Analyses of the perceived difficulty scores (TLX and perceived difficulty scale) revealed no significant difference between groups (all $p \mathrm{~s}>.57$ ), suggesting no between-group difference in the ability to perform the learning task. Analysis of the frequency of goal pursuit scores revealed no significant difference between groups $(p>.25)$ suggesting no between-group difference in the level of expertise to perform the learning task. For each group, mean reaction time was examined with a linear polynomial contrast. The analyses revealed no significant effect (all $p s>$.32). In order to detect potential changes in speed-accuracy trade-off between groups, the arcsinus-transformed proportion of errors in the learning task were examined with a linear polynomial contrast. No effect was found (all $p s>.12$ ). The arcsinus-transformed proportions of errors in the counting task of squares and of triangles were examined with a one-way ANOVA (3 groups). No effect was also found (all $p s>.43$ ).

4. For the priming task, preliminary analyses of covariance (ANCOVAs) found that the midfrequency band baseline values were significantly related to the midfrequency band reactivity scores, $F(1,42)=12.20, p<.001, \eta_{p}^{2}=.24$, and that the high-frequency band baseline values were significantly related to the high-frequency band reactivity scores, $F(1,42)=9.75, p<.003, \eta_{p}^{2}=.20$. Consequently, we adjusted the reactivity scores with respect to the baseline in the further analyses (Lladre, Spitzer, Saab, Ironson, \& Schneiderman, 1991). 
TABLE 1. Means and Standard Deviations of the Baseline of the Cardiovascular Measures as a Function of Groups

\begin{tabular}{lrrr}
\hline & Priming-positive & \multicolumn{1}{c}{ Priming } & \multicolumn{1}{c}{ Control } \\
\hline HR & $68.89(7.12)$ & $71.71(9.11)$ & $68.25(6.31)$ \\
MFB & $357.07(199.12)$ & $457.29(465.97)$ & $440.29(364.71)$ \\
HFB & $386.50(368.21)$ & $386.43(164.71)$ & $528.36(589.66)$ \\
PTT & $185.86(13.57)$ & $185.47(16.19)$ & $190.30(17.84)$ \\
\hline
\end{tabular}

Notes. Standard deviations are in parentheses. HR = heart rate; MFB = midfrequency band; HFB = high-frequency band; PTT = pulse transit time.

Cardiovascular Reactivity. Data of cardiovascular activity are presented in Table $3 .{ }^{5}$ For each group, the heart rate reactivity and high-frequency band reactivity scores were examined with linear polynomial contrasts. For the heart rate reactivity, no effect was significant (all $p \mathrm{~s}>.42$ ). For the high-frequency band reactivity, no effect was significant (all $p \mathrm{~s}>.56$ ), suggesting no potential difference of respiratory activity and parasympathetic nervous system activity between groups.

Midfrequency Band Reactivity. Scores of the midfrequency band reactivity were analyzed with a linear polynomial contrast. We tested a linear relationship for each group. Contrasts weights were +1 for the group tested and 0 for the other groups. A significant linear trend between trials and midfrequency band reactivity scores emerged for the control group, $F(1,38)=11.11, p<.002, \eta_{p}^{2}=.22$. No other linear trend was significant (all $p s>.35$ ). Contrary to the priming-positive group and the priming group, the control group had a linear increase of the midfrequency band reactivity scores across trials (Figure 2).

PTT Reactivity. Scores of the PTT reactivity were analyzed with a linear polynomial contrast. We tested a linear relationship for each group (contrasts weights: +1 for the group tested and 0 for the other groups). A significant linear trend between trials and PTT reactivity scores emerged for the priming group, $F(1,38)=8.62$, $p<.006, \eta_{p}^{2}=.44$. No other linear trend was significant (all $\left.p \mathrm{~s}>.23\right)$.). Contrary to the priming-positive group and the control group, the priming group had a linear increase of the PTT reactivity scores across trials (Figure 3).

Complementary Analysis. A potential difference of ability or level of expertise to perform the task between groups could have influenced the cardiovascular reactivity. To address this issue, we tested for significant associations between the subjective difficulty measures, the frequency of goal pursuit scores and cardiovascular responses. If such associations existed, the reported cardiovascular reactivity for the midfrequency band and the PTT could be explained by differences of ability between groups rather than differences of effort mobilization. Therefore

5. For the learning task, preliminary analyses of covariance (ANCOVAs) found that the midfrequency band baseline values were significantly related to the midfrequency band reactivity scores, $F(1,38)=7.73, p<.008, \eta_{p}^{2}=.17$, and that the high-frequency band baseline values were significantly related to the high-frequency band reactivity scores, $F(1,38)=12.30, p<.001, \eta_{p}^{2}=.24$. Consequently, we adjusted the reactivity scores with respect to the baseline in the further analyses (Lladre et al., 1991). 
TABLE 2. Means and Standard Deviations of the Behavioral and Cardiovascular Data, as a Function of Groups, for the Priming Task

\begin{tabular}{lrrr}
\hline & Priming-Positive & \multicolumn{1}{c}{ Priming } & \multicolumn{1}{c}{ Control } \\
\hline RT & $534.17(50.21)$ & $534.89(41.23)$ & $560.37(86.12)$ \\
ER & $.36(.18)$ & $.34(.08)$ & $.35(.05)$ \\
HR & $73.33(6.52)$ & $74.61(9.50)$ & $73.16(7.27)$ \\
MFB & $252.21(164.77)$ & $338.79(222.56)$ & $377.07(222.70)$ \\
HFB & $283.64(202.42)$ & $392.14(253.50)$ & $440(531.50)$ \\
PTT & $177.72(14.43)$ & $179.14(14.93)$ & $184.12(17.81)$ \\
\hline
\end{tabular}

Notes. Standard deviations are in parentheses. $\mathrm{RT}=$ reaction time; $\mathrm{ER}=$ error rate;

$\mathrm{HR}=$ heart rate; $\mathrm{MFB}=$ midfrequency band; $\mathrm{HFB}=$ high-frequency band;

PTT $=$ pulse transit time.

we considered scores of the TLX scale (Hart \& Staveland, 1988), the perceived difficulty scale (Eccles \& Wigfield, 1995), and the frequency of goal pursuit, as a covariate in separate two-way ANOVAs ( 3 groups $\times 5$ periods of time) for the midfrequency band and the PTT responses. No significant association was found (all $p s>$.22).

Moreover, we tested whether the priming task per se does probably not involve differences between groups of cardiovascular adjustments related to effort mobilization. First, each cardiovascular reactivity score (i.e., heart rate, midfrequency band, high-frequency band, and PTT) was submitted to a 2 (Period: priming task vs. learning task) $\times 3$ (Groups: priming-positive vs. priming vs. control) ANOVA. For each cardiovascular measure, a significant main effect of period was found (all $p \mathrm{~s}<.05$ and all $\eta_{p}^{2} \mathrm{~s}>.09$ ) with a stronger cardiovascular reactivity (i.e., decrease of the PTT, the midfrequency and the high-frequency reactivity scores, and an increase of the heart rate reactivity score), during the learning task compared to the priming task (see Tables 2 and 3). Not surprisingly, as the difference between groups in the learning task appeared across time on task, no effect of groups or interaction was found (all $p s>.35$ ). Moreover, we computed physiological reactivity scores for 5 successive periods of the priming task. Separate 3 (Groups: priming positive vs. priming vs. control) $\times 5$ (Time on Task: 5 successive periods of time) ANOVAs for each cardiovascular measure were carried out. No effect of groups or interaction was significant (all $p$ s $>49$ ).

\section{DISCUSSION}

The present study provides the first evidence that activating the goal of studying through subliminal priming might motivate effortful behavior to learn courses and perseverance across time on coursework, particularly when the goal is coactivated with positive words. Participants in the priming-positive group exhibited a larger decrease of midfrequency band and a larger decrease of the PTT than participants in the control group and the priming group, respectively. In conclusion, participants of the priming-positive group mobilized more effort to their coursework, especially across time on task. These findings replicate the effects obtained by Bargh et al. (2001, Experiment 3) with supraliminal stimuli and extend 
TABLE 3. Means and Standard Deviations of the Subjective, the Behavioral, and the Cardiovascular Data, as a Function of Groups, for the Learning Task

\begin{tabular}{lrrr}
\hline & Priming-Positive & \multicolumn{1}{c}{ Priming } & \multicolumn{1}{c}{ Control } \\
\hline TLX & $7.46(.80)$ & $7.46(.79)$ & $7.32(1.30)$ \\
PD & $15.43(2.06)$ & $14.93(2.13)$ & $14.43(3.11)$ \\
FGP & $14(4.49)$ & $15(2.42)$ & $16.14(2.82)$ \\
RT & $1559.48(311.61)$ & $1561.10(272.16)$ & $1619.79(298.48)$ \\
ERLT & $.76(.51)$ & $.68(.46)$ & $.66(.55)$ \\
ERCS & $.69(.46)$ & $.59(.50)$ & $.67(.28)$ \\
ERCT & $.50(.50)$ & $.46(.53)$ & $.68(.38)$ \\
HR & $76.01(7.41)$ & $77.10(10.96)$ & $74.84(7.06)$ \\
MFB & $204.01(115.86)$ & $377.01(334.91)$ & $373.04(252.39)$ \\
HFB & $203.11(156.18)$ & $273.43(219.80)$ & $273.53(263.07)$ \\
PTT & $174.50(14.46)$ & $177.62(16.33)$ & $183.32(17.04)$ \\
\hline
\end{tabular}

Notes. Standard deviations are in parentheses. TLX = task load index; PD = perceived difficulty; FGP = frequency of goal pursuit; RT = reaction time; ERLT = error rate in learning task; ERCS = error rate in counting the squares; $E R C T=$ error rate in counting the triangles; $\mathrm{HR}=$ heart rate; $\mathrm{MFB}=$ midfrequency band; $\mathrm{HFB}=$ high-frequency band; $\mathrm{PTT}=$ pulse transit time.

them to subliminal stimuli. The priming manipulation was carried out through a word-search puzzle. In the high-performance-goal priming condition, words were related to achievement (e.g., win, succeed). In the other priming condition, words were neutral. Priming participants with an achievement goal influenced on effort mobilization in a subsequent word search task and this priming effect increased across time on task. Taken together, these results suggested that nonconsciously triggered goal pursuits-with supraliminal and subliminal stimuli-carry critical features of consciously guided goal pursuits. According to classic features of goal pursuit (Hockey, 1997; Kahneman, 1973), it is well identified that under demanding conditions consciously goal pursuit involves mobilization of mental resources to counteract the influence of fatigue.

The stronger cardiovascular reactivity of the priming-positive group compared to both the priming group and the control group is interpreted as a higher mobilization of effort. However, participants of the priming-positive group did not obtain better performance than the other groups. This could suggest that participants of the priming and control groups have a greater ability or a higher level of expertise to perform the learning task than participants of the priming-positive group. We rejected this interpretation for several reasons. If participants of the priming and control groups had greater ability to perform the learning task, then they should have perceived the task as easier than participants of the priming-positive group. In the present study, no group difference was found for the TLX scale (Hart \& Staveland, 1988), the perceived difficulty scale (Eccles \& Wigfield, 1995), and the frequency of goal pursuit scale. Differences of ability between groups are typically associated with differences of subjective difficulty and cardiovascular responses related to effort, a pattern we did not observe (for reviews see Wright, 1996; Wright \& Franklin, 2004; Wright \& Kirby, 2001). Moreover, complementary analyses revealed no significant association between TLX, perceived difficulty, and frequency 


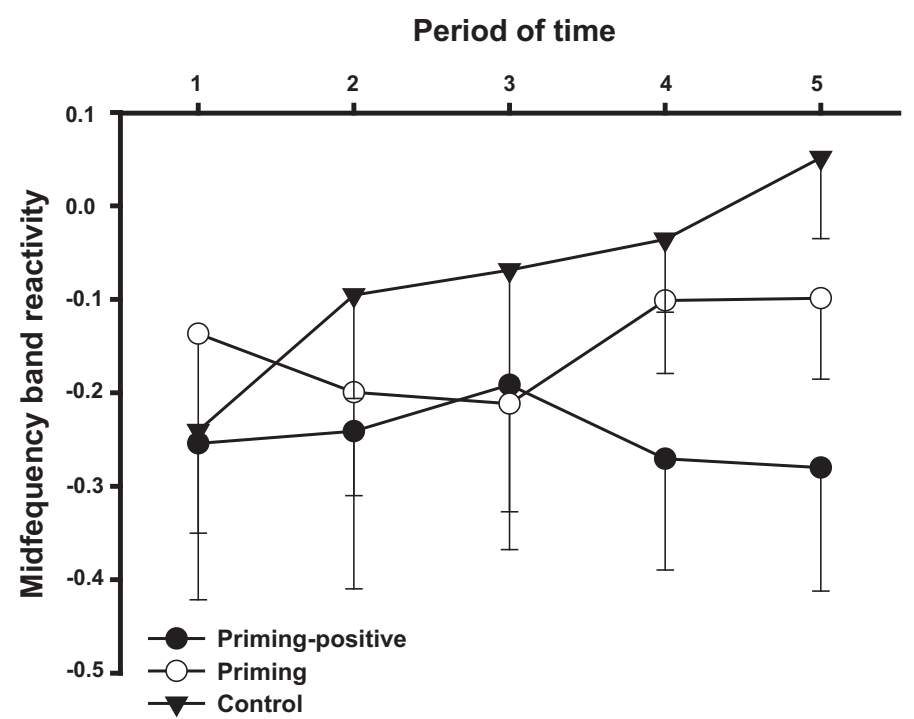

FIGURE 2. Pulse transit time reactivity as a function of groups and the five successive periods of time.

of goal pursuit scores with midfrequency band and PTT responses. Consequently, the cardiovascular reactivity effects obtained for the midfrequency band and the PTT are hardly attributable to potential differences of ability or level of expertise. In the present study, we did not obtain a correspondence between cardiovascular reactivity and performance for the main reason that effort mobilization and performance are not interchangeable constructs. Moreover, with a response every $35.3 \mathrm{~s}$, in the present study; reaction time was not a good index of performance. Performance is the product of effort mobilization, ability and strategy (Locke \& Latham, 2002) and is not a direct measure of resources. This explains why a host of studies showed a greater physiological reactivity related to mental effort mobilization without increase of performance (e.g., Bijleveld, Custers \& Aarts, 2009; Harmon-Jones et al., 2008; Gendolla \& Richter, 2006).

During the priming task, no difference of cardiovascular reactivity between groups appeared, suggesting that the different conditions of priming themselves did probably not involve mobilization of effort. But during the learning taskwhen participants were in a setting that directly offers the possibility to pursue the goal of studying-differences of cardiovascular reactivity related to effort mobilization appeared between groups. These results suggest three important comments. First, this accords with experiments on mood and cardiovascular reactivity related to mental effort mobilization (e.g., Gendolla \& Krüsken, 2001a,b; Richter \& Gendolla, 2009). In these studies, the mood induction technique involved to listen to happy or sad music or write a positive or a negative event, and next participants performed a cognitive task. Cardiovascular reactivity was unaffected during mood induction. However cardiovascular reactivity was affected during the cognitive task. As suggested in the present study, mood does not affect cardiovascular responses directly but affects them by determining how much effort people exert 


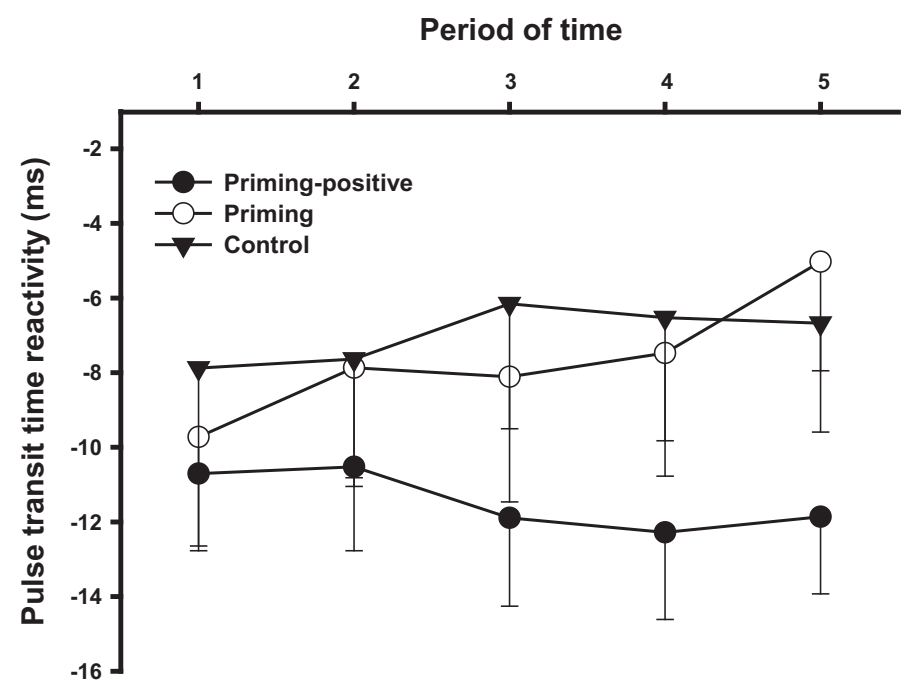

FIGURE 3. Midfrequency band reactivity as a function of groups and the five successive periods of time.

in meeting a challenge. Gendolla and coworkers concluded that they successfully induced relatively long-lasting mood states. Second, our results accord with a recent experiment in which participants were repeatedly exposed to an irrelevant background motion signal so weak that its direction was not visible (Seitz \& Watanabe, 2003). The repetitive exposure improved performance for the direction of the exposed motion in a subsequent suprathreshold test, but only when the motion was associated with a reinforcement acting as a reward. As in the study of Seitz and Watanabe (2003), a direct association between subliminal stimuli and positive valence seems to be a key requirement for the occurrence of long-lasting nonconscious effects. Finally, another potential interpretation of the present results holds that although the effect of subliminal goal priming was nonconscious in nature, it was not a motivational or goal effect but rather a priming of a form of behavior. The theoretical basis for predicting such effect is the mirror-matching system mapping observed actions onto one's own motor system, such that viewing an action automatically evokes a motoric representation in the observer of the motor commands necessary to execute that same action (Jeannerod, 2001; Rizzolatti \& Craighero, 2004). In the present study, we extend results of Aarts, Custers, and Marien (2008), that used a priming of a physical goal to a priming effect of the goal of studying that did not require motor programs. Results of the present study had been unlikely mediated by a priming of perception and action, and suggest an effect of nonconscious activation of the goal to study.

No significant effect of subliminal priming on heart rate reactivity was found. However, as outlined in the introduction, heart rate is both sympathetically and parasympathetically mediated and it is a common finding that heart rate is less sensitive to mental effort mobilization (Obrist, 1981; Wright, 1996). Our cardiovascular predictions were based on the fact that effort mobilization is associated with sympathetic nervous system activity on the heart. Midfrequency band of heart 
rate variability and PTT are probably more valid indicators of the sympathetic nervous system activity. However, these two cardiovascular measures are not the best noninvasive indicators available. Fluctuations of the midfrequency band of heart rate variability are an index of the short-term regulation of blood pressure but are not a direct measure of blood pressure. When people are confronted with performance challenges, an increase of sympathetic nervous system activity is related to task engagement (Obrist, 1981) and induces an increase of blood pressure which may cause a resonance in the veins with a frequency of about $0.10 \mathrm{~Hz}$ (Mulder et al., 1995) and, consequently, a decrease of the midfrequency band (from 0.07 to $0.14 \mathrm{~Hz}$ ). Variability in this band has been shown to decrease during effortful mental tasks (e.g., Capa et al., 2008a, 2008b; Duschek et al., 2009; Fairclough et al., 2005). However, as midfrequency band of heart rate variability is an index of blood pressure pattern, it is also a common finding that this measure is not systematically sensitive to effort investment (e.g., Richter, 2010). Moreover, PTT can only reflect changes in sympathetic nervous system activity if the changes in total peripheral resistance are negligible. Even if our results support our predictions, future researches should aim to test our hypotheses more precisely by considering more reliable and sensitive cardiovascular measures of the sympathetic nervous system activity such as the pre-ejection period (Richter, 2010).

\section{REFERENCES}

Aarts, H., Custers, R., \& Marien, H. (2008). Preparing and motivating behavior outside of awareness. Science, 319, 1639.

Aarts, H., Custers, R., \& Veltkamp, M. (2008). Goal priming and the affective-motivational route to nonconscious goal pursuit. Social Cognition, 26, 555-577.

Aarts, H., Gollwitzer, P., \& Hassin, R. R. (2004). Goal contagion: Perceiving is for pursuing. Journal of Personality and Social Psychology, 87, 23-37.

Askelrod, S., Gordon, D., Ubel, F. A., Shannon, D. C., Barger, A. C., \& Cohen, R. J. (1981). Power spectrum analysis of heart rate fluctuations: A quantitative probe of beat-to-beat cardiovascular control. Science, 213, 220-222.

Bargh, J. A., Gollwitzer, P. M., Lee-Chai, A., Barndollar, K., \& Trötschel, R. (2001). The automated will: Nonconscious activation and pursuit of behavioral goals. Journal of Personality and Social Psychol$o g y, 81,1014-1027$.

Berntson, G. G., Cacioppo, J. T., \& Quigley, K. S. (1993). Cardiac psychophysiology and autonomic space in humans: Empirical perspectives and conceptual implications. Psychological Bulletin, 114, 296-322.

Bijleveld, E., Custers, R., \& Aarts, H. (2009). The unconscious eye opener: Pupil dilation reveals strategic recruitment of resources upon presentation of subliminal reward cues. Psychological Science, 20, 1313-1315.

Capa, R. L., Audiffren, M., \& Ragot, S. (2008a). The effects of achievement motivation, task difficulty, and goal difficulty on physiological, behavioral, and subjective effort. Psychophysiology, 45, 859-868.

Capa, R. L., Audiffren, M., \& Ragot, S. (2008b). The interactive effect of achievement motivation and task difficulty on mental effort. International Journal of Psychophysiology, 70, 144-150.

Custers, R., \& Aarts, H. (2005). Positive affect as implicit motivator: On the nonconscious operation of behavioral goals. Journal of Personality and Social Psychology, 89, 129-142.

Custers, R., \& Aarts, H. (2007). In search of the nonconscious sources of goal pursuit: Accessibility and positive affective valence of the goal state. Journal 
of Experimental Social Psychology, 43, 312-318.

Dehaene, S., Changeux, J. P., Naccache, L., Sackur, J., \& Sergent, C. (2006). Conscious, preconscious, and subliminal processing: A testable taxonomy. Trends in Cognitive Sciences, 10, 204-211.

De Houwer, J., Thomas, S., \& Baeyens, F. (2001). Associtative learning of likes and dislikes: A review of 25 years of research on human evaluative conditioning. Psychological Bulletin, 127, 853-869.

Dijksterhuis, A., \& Aarts, H. (2010). Goals, attention, and (un)consciousness. Annual Review of Psychology, 61, 467-490.

Duschek, S., Muckenthaler, M., Werner, N., \& Reyes del Paso, G. A. (2009). Relationships between features of autonomic cardiovascular control and cognitive performance. Biological Psychology, 81, 110-117.

Eccles, J. S., \& Wigfield, A. (1995). In the mind of the actor: The structure of adolescents' achievement task values and expectancy-related beliefs. Personality and Social Psychology Bulletin, 21, 215-225.

Fairclough, S. H., Venables, L., \& Tattersall, A. (2005). The influence of task demand and learning on the psychophysiological response. International Journal of Psychophysiology, 56, 171-184.

Gendolla, G.H.E., \& Krüsken, J. (2001a). The joint impact of mood state and task difficulty on cardiovascular and electrodermal reactivity in active coping. Psychophysiology, 38, 548-556.

Gendolla, G.H.E., \& Krüsken, J. (2001b). Mood state and cardiovascular response in active coping with an affect-regulative challenge. International Journal of Psychophysiology, 41, 169-180.

Gendolla, G.H.E., \& Richter, M. (2006). Cardiovascular reactivity during performance under social observation: The moderating role of task difficulty. International Journal of Psychophysiology, 62, 185-192.

Harmon-Jones, E., Abramson, L. Y., Nusslock, R., Sigelman, J. D., Urosevic, S., Turonie, L. D., et al. (2008). Effect of bipolar disorder on left frontal cortical responses to goals differing in valence and task difficulty. Biological Psychiatry, 63, 693-698.

Hart, S. G., \& Staveland, L. E. (1988). Development of NASA-TLX (Task Load Index): Results of empirical and theoretical research. In P. A. Hancock \& N. Meshkati (Eds.), Human mental workload (pp. 139178). Amsterdam: North-Holland.

Hockey, G.R.J. (1997). Compensatory control in the regulation of human performance under stress and high workload: A cognitive-energetical framework. Biological Psychology, 45, 73-93.

Jeannerod, M. (2001). Neural simulation of action: A unifying mechanism for motor cognition. Neuroimage, 14, S103-S109.

Kahneman, D. (1973). Attention and effort. Englewood Cliffs, NJ: Prentice-Hall.

Kemper, C. J., Leue, A., Wacker, J., Chavanon, M. L., Hennighausen, E., \& Stemmler, G. (2008). Agentic extraversion as a predictor of effort-related cardiovascular response. Biological Psychology, 78, 191-199.

Koch, C., \& Tsuchiya, N. (2007). Attention and consciousness: Two distinct brain processes. Trends in Cognitive Sciences, 11, 16-22.

Llabre, M. M., Spitzer, S. B., Saab, P. G., Ironson, G. H., \& Schneiderman, N. (1991). The reliability and specificity of delta versus residualized change as measures of cardiovascular reactivity to behavioral challenges. Psychophysiology, 28, 701-711.

Locke, E. A., \& Latham, G. P. (2002). Building a practically useful theory of goal setting and task motivation: A 35-year odyssey. American Psychologist, 57, 705-717.

Mulder, L.J.M., Van Roon, A. M., Veldman, J.B.P., Elgersma, A. F., \& Mulder, G. (1995). Respiratory pattern, invested effort, and variability in heart rate and blood pressure during the performance of mental tasks. In M. Di Rienzo, G. Mancia, G. Parati, A. Pedotti, \& A. Zanchetti (Eds.), Computer analysis of cardiovascular signals (pp. 219-233). Amsterdam: IOS Press.

Naccache, L., Blandin, E., \& Dehaene, S. (2002). Unconscious masked priming depends on temporal attention. Psychological Science, 13, 416-424.

Niskanen, J. P., Tarvainen, M. P., Ranta-Aho, P. O., \& Karjalainen, P. A. (2004). Software for advanced HRV analysis. Computer Methods and Programs in Biomedicine, 76, 73-81.

Obrist, P. A. (1981). Cardiovascular psychophysiology: A perspective. New York: Plenum Press. 
Ravaja, N. (2004). Effects of a small talking facial image on autonomic activity: The moderating influence of dispositional BIS and BAS sensitivities and emotions. Biological Psychology, 65, 163-183.

Richter, M. (2010). Pay attention to your manipulation checks! Reward impact on cardiac reactivity is moderated by task context. Biological Psychology, 84, 279-289.

Richter, M., \& Gendolla, G.H.E. (2009). Mood impact on cardiovascular reactivity when task difficulty is unclear. Motivation and Emotion, 33, 239-248.

Rizzolatti, G., \& Craighero, L. (2004). The mirror-neuron system. Annual Review of Neuroscience, 27, 169-192.

Seitz, A. R., \& Watanabe, T. (2003). Is subliminal learning really passive? Nature, 422, 36.

Task Force. (1996). Heart rate variability: Standards of measurement, physiological interpretation and clinical use. Task force of the European society of cardiology and the north American society of pacing and electrophysiology. Circulation, 93, 1043-1065.

Tomaka, J., Blascovich, J., Kelsey, R. M., \& Leitten, C. L. (1993). Subjective, physiological, and behavioral effects of threat and challenge appraisals. Journal of Personality and Social Psychology, 65, 248-260.
Van den Bussche, E., Hugues, G., Van Humbeeck, N., \& Reynvoet, B. (2010). The relation between consciousness and attention: An empirical study using the priming paradigm. Consciousness and Cognition, 19, 86-97.

Venables, L., \& Fairclough, S. H. (2009). The influence of performance feedback on goal-setting and mental effort regulation. Motivation and Emotion, 33, 63-74.

Wright, R. A. (1996). Brehm's theory of motivation as a model of effort and cardiovascular response. In P. M. Gollwitzer \& J. A. Bargh (Eds.), The psychology of action: Linking cognition and motivation to behavior (pp. 424-453). New York: Guilford.

Wright, R. A., \& Franklin, J. (2004). Ability perception determinants of effort-related cardiovascular response: Mood, optimism, and performance resources. In R. A. Wright, J. Greenberg, \& S. S. Brehm (Eds.), Motivational analyses of social behavior (pp. 187-204). Mahwah, NJ: Lawrence Erlbaum Associates.

Wright, R. A., \& Kirby, L. D. (2001). Effort determination of cardiovascular response: An integrative analysis with applications in social psychology. In M. P. Zanna (Ed.), Advances in experimental social psychology (Vol. 33, pp. 255-307). New York: Academic Press. 
Copyright of Social Cognition is the property of Guilford Publications Inc. and its content may not be copied or emailed to multiple sites or posted to a listserv without the copyright holder's express written permission. However, users may print, download, or email articles for individual use. 